Article

\title{
Communication Studies, Interdisciplinarity Debates, and the Quest for Knowledge
}

Philip O. Onguny, St.Paul University

\begin{abstract}
This article focuses on interdisciplinarity as a "future field" and what it means for the communication discipline. It argues that, whereas interdisciplinarity has the potential to produce "high-risk, high-reward" research outcomes, communication studies has more to gain refining the vast body of knowledge that has shaped its conceptual and institutional particularities across time and space. Whereas this argument is not anything new, I contribute to these debates by emphasizing anthropological questioning, epistemological formulations, ethical reasoning, and the quest for meaning as potential modalities of consolidating the epistemic and political views that have guided the intellectual impetus of communication studies. The proposed refinement is predicated on the assumption that communication studies is already a boundary-crossing discipline; the very reason it arguably lacks coherent historical roots and scientific rationality. The article contributes to the debates on how to operationalize communication studies as a scientific domain without losing its unique boundary-crossing appeal.
\end{abstract}

Keywords: Communication studies, interdisciplinarity, scientific rationality, boundaryspanning, knowledge modalities 


\section{Introduction}

Whereas the debates over interdisciplinarity are not new (Lattuca, Voight and Fath, 2004; Newell, 2001), recent years have seen a strong push for interdisciplinary programs and research design (Herbst, 2008; Klein, 2010; Wang, 2016). The argument has been that boundary disciplines increasingly fall short of providing conclusive assessments of complex systems, and that interdisciplinarity offers a window into transformative forms of knowledge that are useful when seeking to explore and address complex problems (Leahey, Beckman and Stanko, 2017; Reiter, 2017; Van Rijnsoever and Hessels, 2011). Coined as a "high-risk" and "high-reward" undertaking, interdisciplinary research/teams are touted as being innovative and impactful on a wider scale. Accordingly, interdisciplinarity has become the "new philosophy" driving the creation of application-oriented knowledge programs across universities worldwide, including cross-appointment of faculties over the years to keep up with this new trend.

More importantly, granting agencies are shifting their support from disciplinespecific projects to interdisciplinary research design. In the US, for example, the National Institutes of Health $(\mathrm{NIH})$ has been at the forefront of granting exploratory research projects perceived to have transformative potential. The National Science Foundation (NSF) has also emphasized interdisciplinary research collaborations over the years, arguing that "important research ideas often transcend the scope of a single discipline or program ${ }^{1 "}$. Recently, the Canadian tri-council agencies launched their New Frontiers in Research Fund in late 2018, throwing their weight behind interdisciplinarity as a "future field". With the increased push for interdisciplinarity, disciplines such as communication, which already combine several bodies of knowledge, are taking steps to rethink their programs and research strategies.

The International Communication Association (ICA), for instance, decided to focus its 2019 gathering on understanding the role of communication in interdisciplinarity debates, calling for more research that “...spans across particular research domains, and across the boundaries constructed by particular fields of

\footnotetext{
${ }^{1}$ See National Science Foundation (NSF). Introduction to interdisciplinary research. Retrieved from https://www.nsf.gov/od/oia/additional resources/interdisciplinary research/ (March 19, 2019)
} 
research interest" 2 . In fact, all submissions to the 2019 ICA needed to demonstrate their boundary spanning potential. It read: "submissions for the ICA 2019 theme must: focus on the topic of boundary crossing; demonstrate the need for research collaboration across boundaries within communication research and between communication and other disciplines and fields; [and that] panels should include contributions from at least two different countries, and not more than one contribution from a single Faculty, Department or School" ${ }^{3}$. While it is clear that interdisciplinarity is gaining prominence everywhere (i.e. from academic to policy circles), the longstanding question remains whether "students in interdisciplinary courses and programs learn better or learn more than those in discipline-based curricula" (Lattuca, Voight and Fath, 2004, p. 23). Moreover, "what constitutes quality work when individual disciplinary standards are inappropriate or inadequate" remains a subject of debate (Mansilla and Duraising, 2007, p. 215). As academics struggle to make sense of the tilt toward interdisciplinarity, two broad arguments can be discerned.

First, there are those who consider interdisciplinarity as innovative, with transformative potential for high impact. Interdisciplinarity is, in this regard, seen as a creative space for knowledge co-production likely to address complex societal problems that stretch beyond the scope of binary or specialized disciplines (Van Rijnsoever and Hessels, 2011). It broadens the horizons of seeing, thinking, and understanding by allowing for innovative problem-solving perspectives (Wang, 2016; Klein, 2010; Tobi and Kampen, 2018). In this sense, knowledge modalities, however disputed they are, are seen a product of multiple truths or "negotiated consensus" because interdisciplinary research/programs draw upon multiple perspectives to cocreate meaning (Bridle et al. 2013). Emerging disciplines such as sustainability science, emphasizing knowledge co-production as a means to tackle human-nature problems can be seen as a derivative of interdisciplinary research or collaboration (Posner and Cvitanovic, 2019).

Second, much of the discussions against interdisciplinary research or programs revolve around conceptual ambiguities and pedagogical difficulties (Newell, 2001).

\footnotetext{
${ }^{2}$ See International Communication Association (ICA) 2019. Communication beyond boundaries. Retried from https://www.icahdq.org/page/2019CFP (March 8, 2019).

${ }^{3}$ Ibid.
} 
Here, interdisciplinarity is perceived as an exploratory approach lacking disciplinary expertise or scientific rigor that may lead to theoretical and methodological misinterpretations (Kleinberg, 2008). The only sure way of knowing is therefore to equip oneself with conceptual, theoretical, and methodological tools specific to a specific discipline. Consistent with these claims, some have argued that interdisciplinarity is "prominent but less productive" when it comes to scientists' research (Leahey, Beckman and Stanko, 2017). Meanwhile, owing to the scientific culture of certain discipline, others have depicted interdisciplinarity as a zero-sum research undertaking marred by conceptual vagueness and theoretical indecisiveness (Tobi and Kampen, 2018). Because interdisciplinarity invites collaborative research design, some also contend that the "process of generating novel outcomes and the process of those outcomes generating impact may be driven by different mechanisms" (Lee, Walsh and Wang, 2015, p. 685).

Given the opposing positionality, the central question has been how to evaluate the varying modalities of knowing and seeing within interdisciplinary research/programs. Whereas attaining truth is never a straightforward path in scientific fields of study, it is also not uncommon to consider scientific rationality as one of the pillars of true science for it allows for the categorization of disciplines as scientific (Nickles, 2017; Sanchez, 2007). Although questions about scientific rationality are highly disputed, they still invite scholars (irrespective of disciplines) to examine a problem within specific contexts of knowing/seeing. As some observe, this process is mostly determined by how researchers evaluate the "contexts of discovery" and "the context of justification" in contexts of disciplinary research programs (Šešelja, Kosolosky, and Straßer, 2012).

Of course, there is no consensus on what constitutes scientific rationality in the pursuit of disciplinary truths. Historical epistemologists, for instance, hold that the quest for knowing must be grounded in history, and that historiography is key to understanding and/or debunking the myths about science (Sturm, 2011). Such arguments have themselves raised other questions, with some wondering "how can descriptive claims about the past (or present, for that matter) affect our normative judgements about rational beliefs and behaviors?" (Nickles, 2017, para 9). In short, there are disagreements about disagreements when seeking to delimit what constitutes scientific rationality as a path to knowing. One potential explanation for 
these obscurities lies in what we call science, especially what it means, its nature, and core characteristics. As Petrus (2006) puts it, "the way in which science is defined and practised is a monopoly held by the West, and therefore what constitutes valid scientific knowledge is only that which conforms to the Western definition of science" (p. 12). Behavioral scientists such as Skinner (2014) define science as "an attempt to discover order, to show that certain events stand in lawful relations to other event" ( $p$. 6). Meanwhile, francophone scholars such as Fontaine (2008) argue that, "...la science désigne d'abord un savoir-faire procuré par les connaissances jointes à l'habileté, ...[ainsi que] les connaissances acquises sur un objet d'étude plus délimité" (p. 5).

What is important to note in Fontaine's definition is the distinction between "science" and "sciences", which he justifies on the historicity and evolution of knowledge across methods of knowing. This is probably why, in an attempt to understand what constitutes scientific theories, the philosophy of science "asks what the nature and essential characteristics of scientific knowledge are, how this knowledge is obtained, how it is codified and presented, how it is subjected to scrutiny, and how it is warranted or validated" (Machamer, 1998, p. 2). Of course, even the most effective scientific method of knowing cannot guarantee that researchers in the same discipline will agree on delimitation procedures. Disambiguating the scientific nature/characteristic of communication research as well as its rationality is therefore no small chore. Accordingly, "communications research remains split between the embrace of scientific universalism and humanistic focus on contexts and cases, between the pursuit of quantitative precision and interpretative depth" (Calhoun, 2011, p. 1485). This is probably why Nickles (2017) proposes two accounts of scientific rationality: one that considers "radical paradigm change" in science and another which deals with "the relatively smooth change within normal science under a single paradigm" (para. 18).

The question that arises, however, is whether interdisciplinarity subscribes within the logic of "radical paradigm change" or "smooth change within normal science". Nothing seems clear to this end. What is interesting to observe is that even empirical studies on the question of interdisciplinarity have produced mixed and inconclusive evidence on whether interdisciplinarity offers more in terms of knowledge production compared to the narrow or specialized disciplines (Leydesdorff and Probst, 2009; Newell, 2001). In this regard, Lattuca, Voight and Fath (2004) argue that 
evaluating interdisciplinary programs requires a case-by-case approach because "each perspective.... foregrounds different aspects of learning" (p. 29), and that "research and theory suggest that learning will vary depending on how content, pedagogy, and learner characteristics intersect in a course" (p. 44). Meanwhile, Robinson (2008) argues for "issue-driven interdisciplinarity" which integrates practical rationality into the overall evaluation of interdisciplinary potential.

In light of these discussions, what I propose is a set of reflections on potential domains of knowledge around which communication questions can be anchored without losing their unique boundary-crossing appeal or characteristics. While it is reasonable to argue that any efforts to consolidate a body of knowledge for specific disciplinary applications have exclusionary effects, the reflections proposed are an attempt to contribute to the ongoing debates on ways to operationalize communication studies as a scientific domain. I contribute to these discussions by emphasizing anthropological questioning, epistemological formulations, ethical reasoning, and the quest for meaning ${ }^{4}$. The proposed branches of knowledge hold the potential to provide an inclusive structure upon which communication questions can be anchored. Of course, this does not mean adherence to monolithic views. Instead, it invites discussions into the various procedures of knowing, including grounds for acceptance and/or contestation associated with such procedures. The manner in which the modalities of knowledge are approached in a scientific domain often allows for patterned and systematic study of phenomena. It is within this context that the proposed reflections should be understood. Anthropological questioning, epistemological formulations, ethical reasoning, and the quest for meaning can guide the modalities of knowledge upon which communication studies is grounded without compromising its boundary-spanning property - considered here as a strength and an important distinctive feature of communication discipline. In short, the proposed refinement hinges on the assumption that communication studies is already a boundary-crossing discipline, the very reason why it arguably lacks coherent historical roots.

\footnotetext{
${ }^{4}$ The four branches of knowledge are inspired by Expanded Reasons Award, aimed at research that situates scientific rationality and knowledge generation beyond specific or boundary disciplines.
} 
For clarity purposes, the term communication is understood from a constitutive perspective (Cooren, 2012; Craig, 1999; Nicotera, 2009). That is, "to take a constitutive view of communication means to presume that communication, or interaction, is a process of meaning creation or social construction" (Nicotera, 2009, p. 176). The symbolic order of meaning and its embodiment as a form of knowledge therefore rest in communication as a constitutive undertaking. Of course, this does not mean that other perspectives (e.g. transmission and ritual views) - see Rogers (1997), Olson (1989) and Putnam (2001) - offer little in terms of definition. Rather, the reflections proposed align more with constitutive views of communication as a discipline. The term discipline underpins "a branch of instruction, or the educational aspect of a science or art" (Sommer, 2000, p.2). Discipline is thus "the fundamentals on which all knowledge specialties are constructed" (ibid., p.2). Understood as such, Interdisciplinarity refers to "a mode of research by teams or individuals that integrates information, data, techniques, tools, perspectives, concepts, and/or theories from two or more disciplines or bodies of specialized knowledge to advance fundamental understanding or to solve problems whose solutions are beyond the scope of a single discipline or area of research practice" ${ }^{\text {. }}$. Likewise, the term field refers to "an area or sphere of action, operation, or investigation, a subject of activity or specialization" (Sommer, 2000, p. 2). Consistent with these definitions, concentration areas such as international communication are fields within the broader communication discipline.

\section{Communication Studies and the Continued Search for Unifying Themes}

In writing about the problems of identity and originality facing communication studies, Cooren (2012) reminds us that:

[...] it is not enough to notice that this world is shaped and transformed by communication technologies and new forms of communication habits and usages (sociologists, philosophers, psychologists, and anthropologists do that all the time); we also need to provide a communication model of this world, one which would mark the original contribution our field has to offer to the scientific community at

\footnotetext{
${ }^{5}$ Committee on Facilitating Interdisciplinary Research, Committee on Science, Engineering, and Public Policy (2004). Facilitating interdisciplinary research. National Academies. Washington: National Academy Press, $\quad$ p. $2 . \quad$ (cited by NSF https://www.nsf.gov/od/oia/additional resources/interdisciplinary research/definition.jsp)
} 
large, to communication professionals or even to non-specialists (Cooren, 2012, p. 2).

This assertion is among the growing calls by communication scholars to rethink communication discipline and its fields more constitutively whether we see it as a practical, theoretical, or applied area of inquiry. However, the challenge remains the fact that communication is a mosaic and heterogenous discipline (Calhoun, 2011; Craig, 2007/2008; Pooley, 2016; Vorderer and Kohring, 2013). Moreover, and specific to the francophone literature, the articulation of communication studies within the broader "sciences de l'information and de la communication" (SIC) umbrella brings to focus other challenges beyond the discipline's heterogeneity and the notion of science as a "technique" of knowledge creation (Davallon, 2004; Fontaine, 2008; Ollivier, 2001). As Ollivier (2001) puts it, "le champ des SIC produit-il des connaissances si hétérogènes que le champ en apparaîtrait ne pas avoir d'unité scientifique, mais virerait à la pure construction institutionnelle, ou tend-il à une intégration des problématiques et des objets, mouvement qui lui donnerait une figure de discipline, quitte à lui faire perdre de son ouverture originelle ?" (p. 339). Meanwhile, Davallon (2004) warns that "reconnaître l'attache des recherches en sciences de l'information et de la communication à la dimension technique des objets, c'est risquer de réduire son objet de recherche à la fois au monde des choses qui existent effectivement dans la société et à ce commun du sens commun que constitue la notion de "communication»" (p. 31).

These observations show how varied the institutionalization of communication studies has been across regions, adding to the problems of originality, identity, and autonomy associated with communication discipline (Nordenstreng, 2007; Calhoun, 2011; Cooren, 2012; Jiménez and Guillem, 2009). Given these challenges, it is unsurprising to see an increasing number of communication scholars seeking to identify the core bodies of knowledge around which communication questions should be anchored. Of course, there will always be epistemological divisions between branches (fields) of communication such as the frictions between the broader human communication research and the narrower but more strongly institutionalized mass media/communication research (see Couldry, 2013; Corner, 2013; Leydesdorff and Probst, 2009). Although such epistemic divisions must be acknowledged, it is probably 
"an unhealthy illusion to celebrate the popularity of media studies with the distinction of an independent discipline or several disciplines" (Nordenstreng (2007, p. 213).

Despite the continued "soul-searching" within communication studies, there seems to be a shared view that systematizing the vast body of knowledge that has historically informed the discipline remains a challenge across all the communication fields (Littlejohn and Foss, 2010; Wood, 2013). Anyone who has taken a course in communication would certainly agree that knowing what really falls within the purview of communication as a discipline is less straightforward. For this reason, scholars such as Buxton (1996) have argued that these ambiguities have left communication students with "widespread assumptions...that the discipline emerged out of nowhere during the 1930s and 1940s in the United States when a particular set of researchers began to examine the effects of mass communications" (p. 1). Bergman (2012) also points out that, "sometimes viewed as merely a secondary offshoot of sociology or political science, the communication discipline...is marked by self-doubt and periodic 'ferments'" (p. 2). A potential explanation for this, according to Olson (1989), is that "coexisting paradigms mean that few have been rejected in the short life of mass communication as a discipline, but many more are being added" (p. 58). Although Olson makes specific reference to mass communication, the same is true for most if not all communication fields.

Whereas it is commonly accepted that the 1920s, 1930s and, more importantly, 1940s provided temporal focus upon which many situate the historicity of communication discipline (Buxton, 1996; Putnam, 2001; Rogers, 1997; Schramm, 1997; Littlejohn and Foss, 2010; Wood, 2013), issues of normativity in communication research/programs need to be addressed. It is not uncommon to see communication programs emphasize different branches of knowledge depending on areas of interest. This dispersion may be the result of incoherent knowledge base characterizing communication discipline, even though empirical questions are bound to vary based on areas of concentration. An elaborate effort to document historical moments that have shaped communication discipline, particularly the importing/exporting of disciplines, can be found in the works of Zelizer (2016), Park and Pooley (2008), and Jensen and Neuman (2013). While acknowledging the significance of the discipline's historicity, this article is mainly concerned with knowledge modalities that could serve as key reference points - an important step in consolidating the epistemic connections 
among various branches of study that have shaped communication discipline. The objective is to minimize the seeming "cherry picking" approach to knowledge creation adopted by several colleges and universities offering communication programs.

This is not to say that nothing has been done to this end. Several studies have already taken on this important yet challenging task of refining the bodies of knowledge specific to communication discipline. One of the most insightful reflections is provided by Craig (1999), who identifies seven traditions (i.e., rhetorical, semiotic, phenomenological, cybernetic, sociopsychological, sociocultural, and critical) around which communication theories may be hinged. As Maguire (2006, p. 89-90) points out, communication is theorized differently across the seven traditions. It is defined as "the practical art of discourse" in rhetorical tradition, "intersubjective mediation by signs and symbols" in semiotic tradition, "dialogue" in phenomenological tradition, "information processing" through feedback in cybernetic tradition, "expression, interaction and influence" in sociopsychological tradition, "(re)production of social order" in sociocultural tradition, and "discursive reflection" in critical tradition. Although Craig has revised these traditions (e.g., Craig, 2008/2015) in light of the comments and critiques by authors such as Myers (2001), they still offer invaluable insights on the theoretical diversity of communication inquiries. As one can tell, Craig's traditions draw from a vast body of knowledge. Additional reading on each of the proposed traditions might be useful for those seeking to explore these traditions, as they lay the necessary terrain for constitutive models and theories of communication.

Increasingly, discussions about communication theories have centered on pragmatism as a potential unifying theme in communication studies (Cooren, 2014; Craig, 2007; Russill, 2007; Zelizer, 2016). This may explain why, in revisiting his "constitutive metamodel" of communication theory, Craig (2007) included pragmatism to his initial seven traditions. The rationale for this integration is premised on the assumption that pragmatism offers more possibilities with regard to practical orientation of communication theories and their varied interpretations. In fact, francophone scholars such as Cooren (2012) have drawn on Craig's recent works to propose a ventriloquist approach in an attempt to "initiate a dialogue between communication perspectives so that communication theory would become a 'coherent field of metadiscursive practice" (p. 2). For Cooren pragmatism "paves the way to a form of cooperation or dialogue between traditions in spite of their differences" 
(Cooren, 2014, p. 3). Similar arguments are advanced by Russill (2007) who argues for the integration of pragmatist perspectives in communication inquiries over positivist viewpoints because the former offers a problem-oriented approach to communication problems more constitutively. He writes: "communication is not reducible to a fixed set of rules developed for guiding transmission of information or intention, but is better understood as a practice constituted through the encounter of cultural differences and in response to the myriad problems of associative life" (Russill, 2007, p. 127).

Consistent with these discussions, Dewey (2008) views the (re)turn of pragmatism as an "attempt to adapt to the conditions of modern life" initially dominated by absolutism, considering that "a study of the social-scientific exploration of modern society must consider the idea of communication as part of a struggle over positioning the social within human relationships and practices" (p. 33). Pragmatism, in this regard, offers a window into understanding "the conditions and meanings under which people interact" (ibid, p. 35). Pending these discussions, however, there are counterpoints to appropriating pragmatism as a theoretical tradition guiding communication questions. For instance, Bergman (2012) argues that Graig's (2007) integration of the pragmatist thought to previously discussed traditions is less historically-situated and narrow in how it seeks to compartmentalize knowledge modalities. For him, "these exclusions may be detrimental to attempts to tap the full potential of pragmatist thought, and therefore unfavourable to the fruitful development of the communication-theoretical field" (Bergman, 2012, p. 2).

For theorists of cultural studies (CS), there is a dominant belief that "society represents a means of communication based upon which experience gets described, shared, modified and preserved" (Subtil, 2014, p. 21). British cultural studies, for instance, studied "everyday culture" and ideological functions/effects of the media, with most of the intellectual direction provided by the works of Raymond Williams, Richard Hoggart, and Stuart Hall among others. In the US, it is widely accepted that cultural studies was mainly popularized by the works of Lawrence Grossberg. Despite the expansion and variety of topics addressed by the theorists of cultural studies, questions about culture remains at its core and how it engages with areas such as language and signification, text and audience, ideology and hegemony, and identity and subjectivity (Chavez, 2009). However, it is important to point out that 
"contemporarily, cultural studies has fractured into numerous strands of thought that do not share theoretical or methodological unity, although the emphasis on ordinary and popular culture remains central" (ibid., p. 269).

Other important attempts to categorize communication research are found in Hanson's (2010) work, which identifies the common themes studied by communication researchers. For her, three broad themes drive communication research: The first is concerned with "the impact of communication media", which draws upon propaganda research of the 1920s and 1930s as well as public opinion research to examine individual and/or collective attitude formation. The second focuses on "communication flows", with much of the discussions emphasizing crossborder and transnational communication, including how they inform socio-political orders and cross-border relations. The third emphasizes issues of "communication and power", which builds on critical approaches to study communication structures and how they reinforce/weaken dominant ideologies - social, political, or economic. Although Hanson's work underlines international communication, she offers useful insights on how technological advances and political changes have influenced the content and scope of communication discipline across time and space. The interplay between communication and power is also examined by other critical approaches such feminism (see Bellerive and Yelle, 2016), and more broadly, the study of creative and cultural industries within the Franco-Quebecois literature (see Bouquillon, 2014; George, 2014; Miège, 2012; Moeglin, 2012). Scholars such as Bouquillon (2014) argue that, as the notion of culture becomes increasingly fragmented and decentralized, "new" socio-economic agencies (e.g. "inter-channel relations") have emerged thereby altering how culture is conceptualized in both creative industries and creative economies.

Critical orientations to the discipline have provided interesting perspectives on the critique of culture and other "models which reduce communication to processes or states without providing knowledge about how words, or forms of communication, determine an individual's action in social relationships" (Horkheimer, 2008, p. 125). Recent contributions to these discussions can be found in the works McChesney (2007), who believe that little has been done by communication theorists to tap the full potential of Marxism in communication discipline. Taking on this challenge, Fuchs (2010) revisited the "Marxian circuit of capital", particularly as it relates to commodity 
production, commodity circulation, ideology, and alternative media. In essence, Fuchs situates these discussions within the contexts of media-based capitalism. Although there are divergences on questions of agency, it is widely accepted (within the critical tradition) that culture plays a central role in shaping people's ways of knowing. It is often the case that culture, which can be "transported" and/or "transmitted" through media technologies, serves as a rationalizing tool. Studies on cultural commodification subscribe to this very logic (Bunten, 2008). Other discussions and contributions of critical communication studies to the discipline can be found in recent works by Hamilton (2014), and Fuchs (2011).

While these studies provide important insights on the state of communication studies and its conceptual evolution, recent scholarship seems to give up the attempts to streamline the corpus of communication discipline. Yet, if normativity is to be achieved in communication research/programs (see Rothernberger, Auer and Pratt, 2019; Herbst, 2008), one certainly needs to reflect on the ways in which communication questions can be operationalized and systematized. Therefore, even though some may wonder whether "anything has really been achieved by our students and research" (Halloran, 1998), refining the corpus of the discipline is a sure way of consolidating the knowledge base in all communication programs. Although interdisciplinary programs are increasingly becoming popular, it is probably useful for students in every discipline to establish some sort of knowledge thread that unites their ways of seeing and believing - a disciplinary foundation. This does not mean a rupture with other scientific disciplines that have guided the intellectual impetus of communication programs over time and space. Rather, such an approach can provide some sort of coherence with respect to disciplinary knowledge base.

Admittedly, a growing number of studies argue for the establishment of normative guidelines in communication research and programs. Herbst (2008, p. 603), for example, argues that "we need to keep building the field [understood here as discipline], proving our 'value added' on the scholarly scene but, at the same time, remain as broad and open to the offerings of other disciplines as possible". Recent works by Rothernberger, Auer and Pratt (2019, p. 833) also argue for "an explication of communication norms in communication research...to further compare, bridge, and synthesize different perspectives, theories, and methodologies in communication 
scholarship". It is within these contexts that the four branches of knowledge discussed in the next section should be understood/read.

\section{Refining the Corpus and Knowledge Modalities of Communication Studies}

Two broad epistemological orientations seem to guide the discussions on the scientificity of communication discipline. The first views communication studies as an independent full-fledged academic discipline. This position is mainly spurred by the need to develop theoretical and methodological formulations specific to communication discipline given its broad scope (Rogers, 1997; McQuail, 2010). The primary argument is that considering communication discipline as a coherent and independent area of inquiry does not, in principle, suggest any abandonment of the core disciplines that have cultivated its intellectual impetus, but rather allows for the consolidation of its constitutive elements (Kulczycki, 2014; Nordenstreng, 2007). The second epistemological strand emphasizes cross-disciplinary and interinfluence between communication and well-established fields such as philosophy, literary studies, and anthropology. Rather than seeking to establish theoretical/methodological premises specific to communication discipline, studies arguing for this position recognize that communication discipline is both a multidisciplinary and interdisciplinary area of inquiry with "an intricate mosaic composed of parts that are distinct yet interrelated" (Wood, 2013, p. xv). Communication discipline is thus seen as a "bricolage of paradigms" (Olson, 1989).

Given the mosaic nature of communication discipline, Wood (2013) proposes that symbolic activities, meaning, and ethics serve as possible unifying disciplinary themes because they cut across most if not all communication fields. Whether considered a full-fledged or mosaic discipline, others highlight context, form, and medium as potential normative determinants of meaning-making in communication inquiries (Rogers, 1997; McQuail, 2010; Kulczycki, 2014). While acknowledging these epistemological divisions, this article is mainly concerned with potential knowledge base around which these discussions can be take place. The four branches of knowledge proposed (anthropology, epistemology, ethics, and meaning) are seen as important foundations upon which communication inquiries can be grounded while maintaining the dynamism and plurality of knowledge that is unique to the discipline. More importantly, it is the communicative process and interinfluence between these 
branches of knowledge that hold the supreme potential of providing communication discipline with a coherent domain of inquiry.

In a sense, this interaction can allow students in communication to "know at least one specific line of research well and feel competent based on this;...know how to situate this in at least one field of related and complementary lines of research; ...[and] know how to work collaboratively with others who know different things - tools and methods, lines of empirical research, theories" (Calhoun, 2011, p. 1491). To borrow from Cooren (2012), the proposed branches of knowledge should be seen as "communicatively constitutive". That is, they may streamline how communication scholars and students engage, a priori, with the processes of believing, including innate knowledge and innate concepts associated with the discipline. Of course, communication fields will always have different perspectives on how they engage, $a$ posteriori, with empirical questions that are specific to each area of concentration. Admittedly, "the effects of communication on knowledge can vary by medium or the mix of sources that individuals choose, by the motivations and background characteristics of the user, and by the type of knowledge being considered" (Eveland and Garrett, 2014, p. 1). More importantly, "as soon as scholars become aware of their personal (micro level), institutional (meso level), and social (macro level) normative backgrounds, their respective disciplines engage in dialogue with themselves" (Rothernberger, Auer and Pratt (2019, p. 846).

In short, rather than considering the proposed areas as exclusionary, they should be understood as an inclusive structure inviting communication scholars and students to discuss communication questions from a common starting point. This is the underlying expectation behind the four proposed areas of focus.

\section{Communication and anthropological questioning}

In its broadest sense, anthropological questioning revolves around the "act of seeing" or "gazing" (Axel, 2006; Stoller, 1984), thereby inviting people to pay close attention to issues of relativity and nonlinearity in their interactions in time and space. To use Stoller's (1984) words, anthropological inquiry allows one to connect the eye, the mind, and the world. Engaging with anthropological questions requires one to reflect on how people selectively see others with whom they interact, including the meanings they 
associate with social behaviours, verbal or nonverbal. Accordingly, the relationship between communication and anthropology is one that can be described in terms of action situation, "an analytic concept that enables an analyst to isolate immediate structure affecting a process of interest to the analyst for the purpose of explaining regularities in human actions and results, and potentially to reform them" (Ostrom and Ostrom, 2004, p. 117). Social, cultural, and linguistic anthropology, for example, provide a deeper micro-level understanding of what it means to be humans, or how humans understand social interactions in their own logic including the role of culture in shaping that very logic. As Jackson (2008) writes:

To talk about communication as a cultural practice, or of culture as unintelligible without recourse to the manner in which it must get communicated, is to demand a substantive engagement with the inescapable associations between those two constructs: culture, what is learned as opposed to hardwired, shared through verbal and nonverbal interaction, and passed along from generation to generation; communication, variously understood as the transmission of information, as mediations at the kernel of subjectivity and sociality, or as the intersubjective grounding for any and all claims to psychological or social reality (Jackson, 2008, p. 665).

This may explain why communication theorists such as Paul Watzlawick proposed an axiomatic approach to communication, suggesting that "one cannot not communicate" given the constant and continuous exchange of symbols - consciously or not. This is especially true because humans use structures such as language and culture to organize how they see or know. Cultural ways of organizing how we see or know are particularly difficult to grasp. This is why authors such as Jackson (2008) have emphasized "interdisciplinary dialogue" between communication and anthropology, arguing that such an interaction is "an inescapable centrality to any serious engagement with contemporary" (p. 664). Concretely, Jackson invites anthropologists to "sketch out a diverse set of projects and scholarly commitments demonstrating the inextricable ways in which communication-specific questions comprise a portion of the anthropological project at its very core" (p. 664).

In writing about linguistic and cultural anthropology, Axel (2006) also invokes the significance of asking communication-specific questions when seeking to understand how humans interact with communication technologies. A similar approach is taken by 
Coleman (2010) who explores the interconnections "between the local practices and global implications of digital media, their materiality and politics, and their banal, as well as profound, presence in cultural life and modes of communication" (Coleman, 2010, p. 487). Asking anthropological questions may therefore increase students' "act of seeing", while considering the symbolic interaction between humans and their environments because people use descriptive interpretations of their lived experiences to create meaning (Carter and Fuller, 2015). In a sense, a solid background in anthropological inquiry might be useful to communication scholars as they engage with questions relative to our imagined "world of things", as area dominated by semiotics as discussed in Craig's $(1999,2008,2015)$ seven traditions. In short, anthropological questioning invites us to subjectively interrogate social realities while placing meaning within context-specific temporality and spatiality.

\section{Communication and epistemological formulations}

Whereas anthropological questioning brings to focus our ways of "seeing" or "gazing", epistemological formulations allows us to build a clear position vis-à-vis the very acts "seeing" and/or "gazing". In many ways, epistemological clarity is what determines positional connections between the actor, action, and situation, which, for the most part, set up the possibility of our seeing and knowing to be intelligible (Casmir, 1994). Although it is true that disciplinary fields have ontological assumptions specific to them that are devoid of inter-influential forces, one can certainly expect the crossfertilization between communication and epistemological reflection to inform how we relate with facts and evidential truths, including the "degree of fit" between the varying suppositions we hold with respect to our fields of concentration and/or expertise. Ultimately, epistemological questioning allows us to build methodological positioning, which renders our research projects intelligible to others. A clear epistemological position is almost entirely a sine qua non of methodological meticulousness required in any discipline. To put it in Vasilachis de Gialdino's (2009, p.2) terms, "what is usually called science is... a social construction depending on both scientists' beliefs and values and their strict attachment to abstract methods and measures".

So, what does an epistemological grounding add to communication discipline? Without a doubt, it invites a serious discussion about intersubjectivity, which "presupposes that for truth to be valid, it must be derived solely from common human 
experience" (Casmir, 1994, p. 60). However, it is important to note that emphasizing epistemological questions does not suggest the adoption of a universalist approach to seeing/knowing. Rather, it involves constant reflection on how we flesh out objective and subjective seeing and/or knowing. Ideally, epistemological reasoning invites a serious discussion around a "shared epistemic agency" within the confines of disciplinary theories and methods (Damsa et al. 2010). Of course, there are epistemic states that are more salient than others, but we can still question the premises upon which they are formulated. Unlike the too often subjective anthropological reasoning, epistemological positioning calls for a reflection around objective-subjective measure of our worldviews/experience. As such, epistemological questioning provides us with the means to disavow belief functions that draw upon probable beliefs, yet hardly justifiable. This is an important knowledge to have. Casmir (1994, p. 50) pointed out that students in communication often confront four interrelated epistemological problems: those concerned with definitions of science and humanism; those related to the application of paradigm as a scientific concept to study a social science; those relating to intersubjectivity or the links between objective and subjective truths; and finally, those associated with the conceptualization of conceptual evolution in communication discipline.

In sum, epistemological reflections serve as a toolbox for positional connections and their degree of reasonableness. As Vasilachis de Gialdino (2009) points out, "epistemology raises many questions including: 1 . how reality can be known, 2 . the relationship between the knower and what is known, 3. the characteristics, the principles, the assumptions that guide the process of knowing and the achievement of findings, and 4 . the possibility of that process being shared and repeated by others in order to assess the quality of the research and the reliability of those findings" (p. 3.). The overlap between communication and epistemological questioning therefore provides the sparks for mutually constitutive "meaning order" and their degrees of plausibility when discussing communication questions.

\section{Communication and ethical reasoning}

Along with epistemic decisions we have to make in communication studies, we are faced with the difficult question of ethical reasoning, which invites a reflection on the relationship between humans (or non-humans) and their actions. This calls for a careful 
consideration of our moral judgement because it has a profound impact on our research topics, methods, and outcomes. In fact, questions such as what determines newsworthiness are common, yet difficult to answer because we all possess some levels of bias (conscious or not) upon which our ethnical reasoning and choices are predicated. The notion of reasonableness discussed in the previous section therefore lends itself again when it comes to ethical reasoning.

Because the criteria upon which the notions of reasonableness and fairness are hinged is often taken to task, moral scholars such as Rid (2009, p. 12) argue for a "procedural justice" when seeking to determine whether "accountability for reasonableness result in fair limit-setting decisions". Certainly, ethical questions such as determining what fairness is are not straightforward, and have long been debated since Aristotle's "golden mean" about virtuous acts. Zagzebski's (2017), for example, emphasizes exemplarist virtue, suggesting that virtuous acts are primarily a matter of people emulating societal exemplars (e.g. perceived heroes, saints, sages, etc.) and the qualities that bring about trustworthiness or cynicisms about them and their deeds. It is important to note that although Zagzebski believes exemplars serve as markers of moral goodness, she argues for a separation between the values associated with them (e.g. good life) from the judgements they make (e.g. right act). This separation in an important one because it creates room for some "independent" thought regardless of the mainstream ideologies.

Present-day influential political/moral philosophers such as Sandel (2009) also propose that we need to situate our ethical reasoning in contexts of "storied world" because they have largely informed utilitarian, libertarian, and liberal egalitarian choice options that are common and widespread in Western thought. That is, whether our ethical reasoning emphasizes "universal duties that we owe to every human being", "voluntary obligations that we acquire by consent", or "obligations of membership and loyalty...[that] arise simply because of who we are" (Sandel, 2009, p. 14-15), it allows us to assess our own actions within the society. Sandel's work on issues of moral reasoning provides thought-provoking yet stimulating discussions on the most rudimentary topics such as healthcare discussions in the US. Such topics are widely debated in communication courses such as argumentation and persuasion. 
Overall, these discussions show the significance of ethical reasoning in setting up the possibility to evaluate perceived rational choices and their degrees of reasonableness within a given social setting. Since there are conflicting perceptions about what basic ethical value is, sound ethical reasoning may constitute a middle-ofthe-road position with regard to complex societal topics addressed in communication inquiries. Put simply, ethical reasoning influences our choice-worthy variables and their outcomes. These conditions may also be subjected to other condition variables such as divinity and happiness (Bush, 2008), which ultimately inform our ethical acts.

\section{Communication and the quest for meaning}

The quest for meaning is primarily concerned with how we arrange worldly objects in a manner that is meaningful or useful to us. The quest for meaning is almost entirely a matter of semiotics or "intersubjective mediation by signs and symbols" (Maguire, 2006, p. 89) and rhetoric - "the practical art of discourse" (ibid., p. 89). This is because meaning-making is often dependent upon the descriptions we have in our heads whenever we use a term to depict an object. Speaks (2014) identifies two broad ways in which meaning can be attained: the semantic approach, "which assigns semantic contents to expressions of a language" (p. 1) and foundational perspective, "which states the facts in virtue of which expressions have the semantic contents that they have" (p. 1). A semantic quest for meaning is thus concerned with the meanings we attach to and derive from words, symbols, and utterance within a specific system of use. This requires reflection on truth values to establish whether the meaning given to a proposition is true or false. In contrast, foundational meaning creation is concerned with grounds of acceptability. This is probably close to the claim that beauty is in the eyes of the beholder, and thus underscores our inability to propose an objective judgement on propositions with varying degrees of substantiation.

It can therefore be said that the criteria used to arrive at a reasonably shared meaning is what is at the center of debates between boundary disciplines and boundary-spanning disciplines. This is because the interpretations we make of our social world is anchored in social constructs that help us avoid confusions (Zagzebski, 2017). This "anchorage" or "reference point" is largely shaped by the core bodies of knowledge emphasized in a given discipline. In fact, as Wood (2013, p. 23) observes, one fundamental difference between Plato and Aristotle about truth values was that 
the former believed that "truth is absolute and can be known only in ideal forms and not in concrete reality", while the latter assumed that "truth could be discerned from careful observation of concrete reality". For Casmir (1994, p. 54-55), finding meaning in humanist communication requires an examination of three attributes: subjectivity (i.e. "the world is not so much a physical reality unto itself, but a continuity within human consciousness"), evaluation (i.e. "the putting of value into the thing or phenomenon observed [or]...the process of deciding the worth or value of a text, a speech, an action"), and interpretation (which contrasts assumptions of "physical truths", as meaning "builds through interpretation and exegesis and concentrates on texts, since they have the potential to yield a multitude of meanings and readings").

For Wong (2012, p. 5), the quest for meaning is essentially a function of "the meaning mindset... [which] involves understanding the structure, functions, and process of meaning" because people are inevitably "meaning-seeking and meaningmaking creatures" (p. 5-7). This is probably close to Hegelian logic, which perceives "being" as the first stage of human knowledge. If this is true, then meaning formation is itself a communication activity because it is by communicating that "being" is rendered possible. At the core of meaning creation are also the principles of reciprocity and knowledge co-production. Reflecting on reciprocity is important because it influences the norms of acceptability of social behaviors. Knowledge co-production, on the other hand, underpins meaning as a product of negotiated consensus, which brings to focus the discussions around interdisciplinarity (Posner and Cvitanovic, 2019; Tobi and Kampen, 2018). The principles of reciprocity and knowledge co-production thus imply that meaning emerges from communicative processes of reality construction, which calls for a "dialogic turn" as Philips (2011) calls it. French scholars such as Cooren (2012) have also argued for a ventriloquist approach to meaning-making, proposing that communication activities involve "a plethora of agencies" and that "many different things...get communicated when people communicate with each other: ideas, emotions, reflections, knowledge, experiences, cultures, expertise, concerns, preoccupations, but also, and through them, realities and situations" (p. 12).

What do all these mean for communication research/programs? First, engaging with questions of meaning is important because it requires one to reflect on ways to evaluate what constitutes truth values, particularly in a world increasingly imbued by conflicting perceptions over factual truths and negotiated truths. Secondly, 
communication programs play a central role in shaping worldviews by providing training to those who take active part in producing, negotiating, disseminating truths via the media. Reflection on the properties of meaning is thus important. Third, since every scientific domain is concerned with making sense of complex systems (social or not), serious engagement with questions of meaning is likely to increase "normativity in communication research" (see Rothernberger, Auer and Pratt, 2019). The quest for meaning is what brings to focus the question of knowledge modality and the discussions of whether knowledge is absolute, negotiated, individual, or a collective thought. Put differently, it is through the engagement with processes of meaning production, dissemination and consumption that renders our assumptions plausible and/or intelligible to others.

Overall, emphasizing anthropological questioning, epistemological reflections, ethical reasoning and the question of meaning allows for "normative patterns" to emerge within communication programs or research (see Rothernberger, Auer and Pratt, 2019). The long-debated domains of reason in communication studies and their grounds of justification would therefore stem from the interinfluence between these bodies of knowledge. Despite the conceptual and methodological loyalties characterizing the broad fields in communication studies, the proposed bodies of knowledge hold the potential to knit communication discipline together. They can form the core "value issues" in communication studies where students and researchers in communication can find common ground in terms of knowledge base or, at least, have shared areas of interest when probing communication questions. Of course, this does not suggest an abandonment of other disciplinary fields that have influenced communication studies over time and space. Philosophy and theology, for example, have long provided "meaning orders" in many disciplines, including communication investigations (Mowlana, 2003). Philosophical reasoning, for instance, has influenced how we address issues of susceptibility in humankind and society, while theological (and/or religious) arguments have shaped the paragon of virtue, peace, and justice upon which several belief systems are grounded.

\section{Concluding Remarks}

While it is undoubtful that boundary disciplines vary in how they normalize or institutionalize knowledge and the processes of knowing, this article argued that 
emphasizing anthropological questioning, epistemological formulations, ethical reasoning, and the question for meaning has the potential to consolidate the broad and vast body of knowledge that has shaped the corpus of communication as a discipline. This holds the potential to link communication inquiries with normative contexts of discovery and accounts of justification that remain relatively less straightforward to date.

The proposed refinement might also increase epistemic connections between the many strands of communication studies without losing the disciplinary interinfluence between communication and other disciplines, thereby serving as an inclusive structure to discuss communication questions. Put simply, the proposed refinement does not suggest an abandonment of other fields that have informed the conceptual and institutional practices of communication as a scientific discipline. Instead, it takes on the task of identifying ways on how to consolidate the intellectual impetus of communication programs, while maintaining their boundary-crossing particularities.

Overall, the reflections presented here should be read alongside recent works by scholars such as Rothernberger, Auer and Pratt (2019, p. 845-846) who call upon communication researchers to reflect on three normative questions likely to increase the legitimacy and validity of communication inquiries. That is, at the macro-level, "scholars can ask which social norms they adhere to", at meso-level, they "can ask which norms and values of their research institutions, research groups, or schools of thought in communication studies or in the broader scope of social sciences they follow", and at the micro-level, "scholars can clarify the individual norms and values they adhere to, for example in how far their upbringing or their cooperation with other authors influences their own guiding principles".

\section{Acknowledgement}

The author would like to thank Chris Russill and anonymous reviewers for their constructive comments and suggestions on previous versions of this article. 


\section{References}

Axel, B.K. (2006). Anthropology and the new technologies of communication. Cultural Anthropology, 21(3), 354-84.

Coleman, G. (2010). Ethnographic Approaches to Digital Media. Annual Review of Anthropology, 39, 487-505.

Bellerive, K. and Yelle, F. (2016). Contributions des féminismes aux études en communication médiatique. In Aubin, F. and Rueff, J. (eds.), Perspectives critiques en communication: Contextes, théories et recherches empiriques (pp. 279-304). Presses de l'Université du Québec.

Bergman, M. (2012). Pragmatism as a Communication-Theoretical Tradition. European Journal of Pragmatism and American Philosophy, IV-1(2), 1-16.

Bouquillion, P. (2014). Francophone perspectives on creative industries and the creative economy. Canadian Journal of Communication, 39(1), 55-71.

Bridle, H. et al. (2013). Preparing for an interdisciplinary future: A perspective from early-career researchers. Futures, 53, 22-32.

Bunten A. (2008). Sharing culture or selling out? Developing the commodified persona in the heritage industry. American Ethnologist, 35(3), 380-95.

Bush, S. (2008). Divine and Human Happiness in Nicomachean Ethics. Philosophical Review, 117, 49-75.

Calhoun, C. (2011). Communication as a social science (and more). International Journal of Communication, 5, 1479-1496.

Carter, M.J. and Fuller, C. (2015). Symbolic interactionism. Sociopedia.isa, 1-17.

Casmir, F. L. (1994). Building communication theories: A socio-cultural approach. Hillsdale, NJ: Erlbaum. 
Cooren, F. (2012). Communication theory at the center: Ventriloquism and the communicative constitution of reality. Journal of Communication, 62(1), 1-20.

Cooren, F. (2014). Pragmatism as ventriloquism: Creating a dialogue among seven traditions in the study of communication. Language Under Discussion, 2(1), 1-26

Corner, J. (2013). Is there a "field" of media research? The "fragmentation" issue revisited. Media, Culture \& Society, 35(8), 1011-1018.

Couldry, N. (2013). If not a single field, then what? Media, Culture \& Society, 35(8), 1023-1026.

Craig, R. T. (1999). Communication theory as a field. Communication Theory, 9(2), 119161.

Craig, R. T. (2007). Pragmatism in the Field of Communication Theory. Communication Theory, 17 (2), 125-45.

Craig, R. T. (2008). Communication as a field and discipline. In W. Donsbach (Ed.), The international encyclopedia of communication (pp. 675-688). Oxford, UK: Blackwell.

Craig, R. T. (2015). The constitutive metamodel: A 16 year review. Communication Theory, 25(4), 356-374.

Damsa, C.I. et al. (2010). Shared epistemic agency: An empirical study of an emergent construct. Journal of the Learning Sciences, 19(2), 143-186.

Sturm, T. (2011). Historical Epistemology or History of Epistemology? The Case of the Relation Between Perception and Judgment. Erkenn 75, 303-324

Davallon, J. (2004). Objet concret, objet scientifique, objet de recherche. Hermès, $1(38), 30-37$. 
Dewey, J. (2008). On discovering communication: Pragmatism and the pursuit of social criticism. In D. Hardt (ed.). Critical essays in communication (chapter 2). London: Routledge.

Eveland, W. P., \& Garrett, R. K. (2014). Communication modalities and political knowledge. In K. Kenski \& H. J. Kathleen (Eds.), The Oxford handbook of political communication. Oxford, NY: Oxford University Press.

Fontaine, P. (2008). Qu'est-ce que la science ? De la philosophie à la science: les origines de la rationalité moderne. Recherche en soins infirmiers, 92(1), 6-19.

Fuchs, C. (2011). Foundations of Critical Media and Information Studies. New York: Routledge.

Fuchs, C. 2010. Grounding Critical Communication Studies: An Inquiry into the Communication Theory of Karl Marx. Journal of Communication Inquiry 34 (1): 1541.

George, E. (2014). The theory of the cultural industries: A "milieu" for building dynamic knowledge. Canadian Journal of Communication, 39(1), 29-54.

Halloran, J.D. (1998). Social science, communication research and the third world. Media Development, (2), 43-46.

Hamilton, S. N. (2014). Considering critical communication studies in Canada. In L. R. Shade (Ed.), Mediascapes: New patterns in Canadian communication (4th ed.), (pp. 4-24). Toronto, ON: Nelson Education.

Hanson, E.C. (2010). A History of International Communication Studies. In R. Denemark (ed). The International Studies Encyclopedia (vol 6: pp. 3396-3417). Oxford: Wiley-Blackwell.

Herbst, S. (2008). Disciplines, intersections, and the future of communication research. Journal of Communication, 58(4), 603-614. 
Horkheimer, M. (2008). On introducing ideology: Critical Theory and the critique of culture. In D. Hardt (ed.). Critical essays in communication (chapter 2). London: Routledge.

Jackson, J.L. (2008). Toward an Ethnographic Lingua Franca: Communication and Anthropology, Journal of Communication, 58(4), 664-678.

Jacobs, J. A., \& Frickel, S. (2009). Interdisciplinarity: A critical assessment. Annual Review of Sociology, 35(1), 43-65.

Jensen, C. B. \& Neuman, W. R. (2013). Evolving Paradigms of Communication Research. International Journal of Communication 7 (2013), Feature: 230-238.

Jiménez, G.L. \& Guillem, M.S. (2009). Does communication studies have an identity? Setting the bases for contemporary research. Catalan Journal of Communication \& Cultural Studies, 1 (1), 15-27.

Klein, J. T. (2010). Creating interdisciplinary campus cultures: A model for strength and sustainability. San Francisco, CA: Jossey-Bass.

Kleinberg, E. (2008), Interdisciplinary studies at a crossroads. Liberal Education, 94 (1), 6-11.

Kirby, A. (2019). Transdisciplinarity and sustainability science: A response to Sakao and Brambila-Macias in the context of sustainable cities research. Journal of Cleaner Production, 210, 238-245.

Kulczycki, E. (2014). Communication History and Its Research Subject. Analele Universitatii din Craiova, Seria Filosofie, 33(1), 132-55.

Lattuca, L.R., Voigt, L.J. \& Fath, K.Q. (2004). Does interdisciplinarity promote learning? Theoretical support and researchable questions. The Review of Higher Education, 28(1), 23-48. 
Lee, Y.N., Walsh, J.P., \& Wang, J. (2015). Creativity in scientific teams: Unpacking novelty and impact. Research Policy, 44, 684-697.

Leydesdorff, L., \& Probst, C. (2009). The delineation of an interdisciplinary specialty in terms of a journal set: The case of communication studies. Journal of the American Society for Information Science and Technology, 60(8), 1709-1718.

Littlejohn, S. W., \& Foss, K. A. (2010). Theories of human communication (10 th ed.). Belmont, CA: Thomson Wadsworth.

Machamer, P. (1998). Philosophy of science: An overview for educators. Science \& Education, 7, 1-11.

Maguire, K. C. (2006). Making Sense of the Seven Communication Traditions. Communication Teacher, 20(4), 89-92.

Mansilla, V.B. \& Duraising, E. D. (2007). Targeted assessment of students' interdisciplinary work: an empirically grounded framework proposed. Journal of Higher Education, 78, 215-37.

McQuail, D. (2010). Mcquail's mass communication theory. Thousand Oaks, CA: SAGE Publications.

Mielke, J. et al. (2016). Stakeholder involvement in sustainability science: A critical view. Energy Research \& Social Science, 17, 17-81.

Miège, B. (2012). La théorie des industries culturelles (et informationnelles), composante des SIC. Revue française des sciences de l'information et de la communication. Online URL: http://journals.openedition.org/rfsic/80

Mœglin, P. (2012). Une théorie pour penser les industries culturelles et informationnelles? Revue française des sciences de l'information et de la communication, 1, 1-11. 
Mowlana, H. (2003) Communication, philosophy and religion. Journal of International Communication, 9(1), 11-34.

Myers, D. (2001). A pox on all compromises: Reply to Craig (1999). Communication Theory, 11, 231-240.

Newell, W. (2001). A theory of interdisciplinary studies. Issues in Integrative Studies, 19, 1-25.

Nickles, T. (2017). Historicist Theories of Scientific Rationality. In E.N. Zalta (ed.) The Stanford Encyclopedia of Philosophy (Summer 2017 Edition). Retrieved from https://plato.stanford.edu/archives/sum2017/entries/rationality-historicist

Nicotera, A. (2009). Constitutive view of communication. In S.W. Littlejohn \& K.A. Foss (Eds.), Encyclopedia of communication theory (Vol. 1, pp. 176-179). Thousand Oaks, CA: SAGE Publications, Inc.

Nordenstreng, K. (2007). Discipline or field? Soul-searching in communication research. Nordicom Review, 28, 211-222.

Ollivier, B. (2001). Enjeux de l'interdiscipline. L'Année sociologique, 51(2), 337-354.

Olson, S. (1989). Mass Communication: A bricolage of paradigms. In S. King (ed.), Human Communication as a Field of Study: Selected contemporary views (pp. 5786). Albany, NY: Sate University of New York Press.

Ostrom, E., \& Ostrom, V., (2004). The quest for meaning in public choice. American Journal of Economics and Sociology, 63(1), 105-146.

Park, D. \& Pooley, J. (2008). The History of Media and Communication Research: Contested Memories. New York: Peter Lang.

Petrus, T.S. (2006). Engaging the World of the Supernatural: Anthropology, Phenomenology and the Limitations of Scientific Rationalism in the Study of the Supernatural. Indo-Pacific Journal of Phenomenology, 6(1), 1-12. 
Phillips, L. (2011). The promise of dialogue: The dialogic turn in the production and communication of knowledge. Amsterdam, The Netherlands: John Benjamins Publishing.

Pooley, J.D. (2016). Open Media Scholarship: The Case for Open Access in Media Studies International Journal of Communication, 10, 6148-6164.

Posner, S., \& Cvitanovic, C. (2019). Evaluating the impacts of boundary-spanning activities at the interface of environmental science and policy. Environmental Science \& Policy, 92, 141-151.

Putnam, L.L. (2001). Shifting voices, oppositional discourse, and new visions for communication. Journal of Communication, 51(1), 38-51.

Reiter, B. (2017). Theory and methodology of exploratory social science research. International Journal of Science and Research Methodology, 5(4), 129-150.

Rid, A. (2009). Justice and procedure: how dose "accountability for reasonableness" result in fair limit-setting decisions? J Med Ethics, 35, 12-16.

Rogers, E. M. (1997). A history of communication study: a biographical approach. New York: Free Press.

Rothenberger, L., Auer, C. \& Pratt, C.B. (2019). Identifying Normativity in Communication Research: A Typology and a Framework for Assessing Scientific and Extrascientific Norms. International Journal of Communication, 13, 833-852.

Russill, C. (2007). Communication Problems in a Pragmatist Perspective. Communication Monographs, 74 (1), 125-30.

Sanchez, C. (2007). The Nature of Belief and the Method of Its Justification in Husserl' Philosophy. Indo-Pacific Journal of Phenomenology, 7(2), 1-10.

Sandel, M. (2009). Justice: What's the right thing to do. New York: Farrar, Straus and Giroux. 
Šešelja, D., Kosolosky, L. \& Straßer, C. (2012). The Rationality of Scientific Reasoning in the Context of Pursuit: Drawing Appropriate Distinctions. Philosophica, 86, 51-82.

Schramm, W. (1997). The beginnings of communication study in America: A personal memoir. S. Chaffee \& E. M. Rogers (Eds.). Thousand Oaks, CA: Sage.

Skinner, B.F. (2014). Science and human behavior. The B. F. Skinner Foundation.

Sommer, R. (2000). Discipline and field of study: A search for clarification. Journal of Environmental Psychology, 20, 1-4.

Speaks, J. (2014). Theories of meaning. In Zalta, E.N. (Ed.), The Stanford Encyclopedia of Philosophy, http://plato.stanford.edu/archives/sum2011/entries/meaning/

Stoller, P. (1984). Eye, Mind and Word in Anthropology. In L'Homme, 1984, tome 24, $n^{\circ} 3-4,91-114$.

Tobi, H., \& Kampen, J. K. (2018). Research design. Quality and quantity: international journal of methodology, 1209-1225.

Van Rijnsoever, F.J. \& Hessels, L.K. (2011). Factors associated with disciplinary and interdisciplinary research collaboration. Research Policy, 40, 463-472.

Vasilachis de Gialdino, I. (2011). Ontological and Epistemological Foundations of Qualitative Research. Qualitative Social Research, 10, 2, Art. 30.

Vorderer, P. \& Kohring, M. (2013). Permanently online: A challenge for media and communication research. International Journal of Communication, 7, 188-196.

Wang, J. (2016). Knowledge creation in collaboration networks: Effects of tie configuration. Policy Research, 45(1): 68-80.

Wood, J. (2013). Communication Mosaics: An Introduction to the Field of Communication ( $7^{\text {th }}$ edition). Cengage Learning. 
Wong, P.T. (Ed.). (2012). The human quest for meaning. Routledge, Taylor \& Francis.

Zagzebski, L. (2017). Exemplarist Moral Theory. Oxford: Oxford University Press.

Zelizer, B. (2016). Communication in the fan of disciplines. Communication Theory, 26(3), 213-235. 